\title{
Preservice teacher mobile investigation and interpretation of everyday mathematics across settings
}

\author{
Manuscript preprint. \\ Article in press, to appear in Journal of Technology and Teacher Education. \\ Questions concerning this manuscript should be addressed to: \\ Jeremiah H. Kalir \\ Assistant Professor, Information and Learning Technologies \\ School of Education and Human Development \\ University of Colorado Denver \\ 1380 Lawrence St., Room 645 \\ Denver, CO 80204 \\ remi.kalir@ucdenver.edu \\ Office: (303) 315-0034 \\ www.remikalir.com
}

\begin{abstract}
This study reports upon design-based research that enacted mobile mathematics learning for preservice teachers across classroom, community, and online settings. The integration of mobile learning within mathematics teacher education is understudied, and it is necessary to better understand mobile technology affordances when locating disciplinary inquiry across settings. A curriculum module was designed to support preservice teachers' participation in two mathematics education and mobile learning repertoires: a) mobile investigation of disciplinary concepts situated in community locations and circumstances, and b) mobile interpretation of connections between school and everyday mathematics. This exploratory case study analyzes three module iterations and identifies the qualities of preservice teachers' cross-setting disciplinary connections. Reported mobile learning outcomes include connections preservice teachers produced among mathematics concepts, mathematical actions, and material objects, and also connections produced between school mathematics and everyday circumstances. Findings indicate preservice teachers established disciplinary connections when participating in commercial and civic activities relevant to their daily lives. Yet other mathematics concepts and practices were either seldom investigated, only vaguely described, or not representative of K-12 students' interests and cultures. Design recommendations and implications are suggested for subsequent attempts at situating preservice teacher learning outside of the mathematics teacher education classroom and across multiple settings through mobile learning.
\end{abstract}

Keywords: Mobile learning, digital media, mathematics education, teacher education, design-based research, settings 
There exists an enduring concern that student learning inside school reflect and connect with everyday out-of-school experiences. The oft-cited adage from John Dewey (1897) captures this sentiment: "I believe that the school must represent present life - life as real and vital to the child as that which he carries on in the home, in the neighborhood, or on the playground" (p. 7). Whether for reasons of equity, cultural relevance, or career-readiness, varied frameworks and pedagogies seek to connect K-12 student learning across settings and practices, both formal and informal (e.g. Banks et al., 2007; Ito et al., 2013). Enthusiasm associated with digital media practices (e.g. Garcia, 2014) or scientific practices (e.g. Penuel, 2014), however, appear less developed in mathematics education. A persistent disconnect - evident in student problem solving, tool use, and evaluation - exists among how school mathematics is conceptualized and taught, if it connects to so-called real world mathematics, and whether new pedagogies can bridge this gap (Civil, 2014; Martin \& Gourley-Delaney, 2014).

Recently, the ubiquity of mobile devices - accompanied by theoretical and empirical development in mobile learning across settings - has rejuvenated attempts to connect school with everyday mathematics (e.g. White \& Martin, 2014; Wijers, Jonker, \& Drijvers, 2010). White and colleagues (2011) assert that mobile devices are capable of bridging "gaps between formal and informal learning in mathematics" (p. 11) by connecting disciplinary inquiry across multiple school, community, cultural, and online settings. Mobile devices, they suggest, support four "repertoires" of digital media and mathematical practices that span such settings: capturing and collecting; communicating and collaborating; viewing, consuming, and analyzing; and designing and creating. Drawing upon White and colleagues' repertoire as a scaffold for empirical study at the intersection of mobile learning and mathematics teacher education, this article reports on design-based research (Cobb, Confrey, diSessa, Lehrer, \& Schauble, 2003) that iteratively designed and enacted mobile mathematics learning for preservice teachers (PSTs) in an attempt to both situate and connect disciplinary inquiry across school and everyday settings. 
This study investigates PST learning via the curriculum module Mapping My Math (MMM; Author, 2016) and identifies discipline-specific connections among school and everyday mathematics produced by PSTs when cross-setting mobile learning was integrated into teacher preparation. MMM enabled PSTs to demonstrate two repertoires of mobile learning practices that are mathematical (White et al., 2011). First, MMM supported mathematical mobile investigation by encouraging PSTs to capture and collect "information and experiences across a variety of settings, through photos, audio and video recordings, numerical and text entry, and other inputs, as well as tagging and cataloging what is found" (p. 8). Second, MMM also guided mathematical mobile interpretation by supporting PSTs to design and create "personal forms of representation and expression such as digital artwork, digital films, photo slide shows or archives, and blogs or other written reflections" (ibid). An analysis of PST learning during three MMM iterations identifies the prevalence, qualities, and limitations of disciplinary connections produced via mobile investigations and interpretations of everyday mathematics across settings.

\section{Perspectives on Mobile Learning Across Settings}

Despite quotidian reference to learning anytime and anywhere, mobile learning is not synonymous with activity that occurs outside a traditional classroom and across settings. Two traditions of sociocultural theory, however, help frame mobile learning as participation in social, cultural, and disciplinary practices connected across multiple settings. This study approaches mobile mathematics learning as reflective of both situated and constructivist views of learning. First, learning may first be understood as socially situated in conversations, coordinated in action, and embedded in particular circumstances (Lave \& Wenger, 1991). Given shared purpose, different social relations and whether in or outside of school - shape how people participate in a "nexus of activity, tool, and culture," and hence how they learn (Brown, Collins, \& Duguid, 1989). Learning is also materially situated, distributed across conceptual tools (such as disciplinary conventions), physical objects (like 
mobile devices), and the environment (whether a café or chat forum). Second, ideas of constructivism further suggest learners actively create knowledge through meaningful interactions with their peers and mentors in designed and everyday environments (Fosnot, 2013). The active construction of knowledge can occur among diverse settings and practices, including, for example, children's mathematical discussions inside a classroom (Yackel \& Cobb, 1996) as well as discipline-specific mobile learning investigations outside of a classroom (Squire, 2010). Together, situated and constructivist views of learning help to conceptualize mobile, mathematics, and also (preservice) teacher learning as occurring across multiple settings to connect school with everyday knowledge and practice.

\section{Literature Review}

The extent to which mobile learning is a means for exploring and modeling cross-setting disciplinary inquiry remains contested and unresolved. Distinct from literature primarily focused upon mobile device features, recent research has jettisoned the classroom as a learning container to consider the social and contextual opportunities of mobile learning (e.g. Squire, 2013). This approach remains complicated as, according to van’t Hooft (2013), “Current developments in mobile learning have not provided a solid foundation for a clear theory or definition as of yet" (p. 177). Sharples and colleagues (2007) do offer one broadly recognized mobile learning definition: "The processes of coming to know through conversations across multiple contexts amongst people and personal interactive technologies" (p. 4). Here, a "conversation" suggests knowledge is constructed when learners, their interests and goals, and devices and information interact across settings. That conversations are instantiated and reverberated "across multiple contexts" is echoed in Squire's (2009) attention to the “multiplicity of place." A hallmark of mobile learning can be support for practices that connect the multiple places of home, school, and community via interest-driven learning and peer relations, affording the exploration of disciplinary concepts and practices across settings (White et al., 2011). 
When mobile learning traverses space, time, and tradition, it has been perceived to threaten the current order of schooling (Squire, 2010).

The confluence of mobile learning and K-12 mathematics education exhibits similar tensions in regards to setting, pedagogy, and purpose. Mobile device use in mathematics education has concerned calculator use, access to content, and, more recently, networks and generative activities among groups, online spaces, and content domains (e.g. Carmona et al., 2011). In many cases, device functionality rather than mobility and learning across settings - appears to influence mathematics content delivery, teaching practices, and research. In two reviews of "exemplar" mobile learning projects (Squire, 2013; van't Hooft, 2013), school-based mathematics education was disconnected from learners' out-of-school activity. Little research has examined mobile learning as a viable means of connecting school mathematics with everyday settings and practices. One exception is Wijers and colleagues (2010), who found that students' disciplinary engagement was supported by a game layered "on top of the physical reality by drawing shapes" (p. 797). Additionally, Martin and Gourley-Delaney (2014) examined how middle school students' photography of everyday mathematics was judged to be mathematical during school-based group and online activities. In spite of these few examples, mathematics educators seldom leverage the portable affordances of mobile devices for cross-setting investigation and interpretation. Assessing mobile learning in mathematics education, White and Martin (2014) observe: "When mobiles are incorporated into classroom settings, they are often used in limited ways, such as to reproduce existing school functions, acting as calculators, calendars, or textbooks" (p. 64). In contrast to mobile learning efforts situating inquiry beyond school walls, mobile learning infrequently dislodges mathematics education from the K-12 (or teacher education) classroom. Mobile learning efforts in mathematics education generally appear resistant to mediating disciplinary connections across multiple settings. 
Further motivating this study, a thin research base has investigated mobile learning in teacher education across settings. Research at the intersection of mobile learning and teacher education has frequently privileged device-centric technical affordances over cross-setting activity. Ferry (2009) implicitly bridges settings by observing how PSTs used recording features (i.e. video, audio) and text messaging for immediate feedback and support from peers. However, as Bull and colleagues (2008) assert, in order "to translate informal use of communication technologies outside school into applied activities inside school, educators must consider content and the pedagogies best suited for bridging these in- and out-of-school uses of technology. Schools of education provide a natural entry point for considering possible approaches for accomplishing this" (p. 104). Mobile learning in teacher education remains understudied, particularly as concerns PST exploration and representation of disciplinary concepts and practices while moving among everyday and academic settings.

\section{Research Question}

There are several reasons why mathematics teacher education is a useful context for studying PST mobile investigation and interpretation as a strategy for establishing disciplinary connections across settings. First, mobile learning research within mathematics education predominantly concerns student, and not teacher, learning. Second, despite some mathematics (teacher) educators situating PST inquiry among everyday communities and cultures (e.g. Aguirre et al., 2013; Gutiérrez, 2012), the integration of educational technology (much less mobile devices) within this literature is largely absent. It is necessary to better understand the role of technology in situating mathematical inquiry across settings and as connected to learners' lives. Third, while tools are but one component of constructivist approaches to mathematics education, research routinely indicates PSTs seldom learn how to effectively or creatively teach (mathematics) with technology (e.g. Martinovic \& Zhang, 2012). There remains a need to provide PSTs with digital learning experiences they likely did not experience in their prior mathematics education (e.g. Carmona et al., 2011). The mobile learning, mathematics education, 
and teacher education literatures evidence both opportunity and limitation; these insights motivate the current research agenda. Accordingly, this exploratory case study asks: What types of disciplinary connections between school and everyday mathematics do preservice teachers (PSTs) produce through their mobile investigation and interpretation across settings?

\section{Methodology}

This analysis of PST learning in MMM draws upon a larger design-based research study that examined the affordances of place, digital media, and mobility in mathematics teacher education. The design and enactment of MMM took place in one elementary mathematics methods course within the teacher education program of a large research university. The course encouraged PSTs to connect everyday with school mathematics through cooperatively planning and teaching content- and gradespecific lessons, rehearsing pedagogical strategies, discussing literature, and completing group and individual projects (e.g. Gutiérrez, 2012). In addition to my role as researcher, I co-taught the course for four semesters. This study utilizes data from three semesters and MMM iterations: Spring 2012 (M1, n=25); Fall 2012 (M2, n=24); and Spring 2013 (M3, n=24). PSTs were undergraduates in their early 20 s who were mostly female (61 of $73,84 \%$ ) and largely self-identified as White/EuropeanAmerican (68 of $73,93 \%)$.

\section{Design, Enactment, and Iteration of Mapping My Math}

MMM integrated cross-setting mobile learning into mathematics teacher education by encouraging PST to experience Stevens' (2013) in-not-as problematic. While learners typically study mathematics as activity primarily for schooling, school exercises can be distinguished from mathematics in activity, or practices revealed in professional activities and settings, deployed in daily transactions, and expressed by people in everyday situations. Complementing mobile learning repertoires of capturing and collecting media, and also representing mathematics inquiry (White et al., 2011), MMM mobile investigation and interpretation activities helped PSTs to practice making 
connections between school-based mathematics as activity and everyday mathematics in activity. Four MMM activities were designed and implemented over a period of approximately one month to guide PST in practicing how to make these connections. Table 1 summarizes MMM activities, duration, settings, objectives, and learning technologies.

Table 1: Summary of Mapping My Math activities across iterations

\begin{tabular}{|c|c|c|c|c|}
\hline MMM activity & Duration & Settings & Objective & Learning technologies \\
\hline $\begin{array}{l}\text { Activity 1: } \\
\text { Discuss literature } \\
\text { online }\end{array}$ & $\begin{array}{l}1 \text { week } \\
\text { (all iterations) }\end{array}$ & Online: Wiki & $\begin{array}{l}\text { PSTs discuss \& analyze } \\
\text { place-based approaches to } \\
\text { mathematics education; } \\
\text { introduction to everyday } \\
\text { mathematics literature }\end{array}$ & Computers, literature \\
\hline $\begin{array}{l}\text { Activity 2: } \\
\text { Mobile } \\
\text { investigation of } \\
\text { everyday } \\
\text { mathematics in } \\
\text { community }\end{array}$ & $\begin{array}{l}1 \text { hour } \\
\text { (all iterations) }\end{array}$ & $\begin{array}{l}\text { Community, } \\
\text { Online: mobile } \\
\text { communication }\end{array}$ & $\begin{array}{l}\text { PSTs capture and collect } \\
\text { media during community- } \\
\text { based investigations of } \\
\text { everyday mathematics }\end{array}$ & $\begin{array}{l}\text { Mobile phones, maps, } \\
\text { paper, pencil/pen, \& } \\
\text { "everyday" objects } \\
\text { encountered during } \\
\text { investigations }\end{array}$ \\
\hline $\begin{array}{l}\text { Activity } 3 \text { : } \\
\text { Prototype mobile } \\
\text { interpretations in } \\
\text { the classroom }\end{array}$ & $\begin{array}{l}0 \text { min. }(\mathrm{M} 1), \\
30 \min .(\mathrm{M} 2), \\
1 \text { hour }(\mathrm{M} 3)\end{array}$ & Classroom & $\begin{array}{l}\text { PSTs begin designing } \\
\text { interpretive digital media } \\
\text { via paper prototype }\end{array}$ & $\begin{array}{l}\text { Paper (prototyping } \\
\text { template), mobile media, } \\
\text { pencil/pen }\end{array}$ \\
\hline $\begin{array}{l}\text { Activity } 4 \text { : Create } \\
\text { mobile } \\
\text { interpretations } \\
\text { online }\end{array}$ & $\begin{array}{l}1 \text { week (M1), } \\
1 \text { week (M2), } \\
2 \text { weeks (M3) }\end{array}$ & $\begin{array}{l}\text { Online: Wiki, } \\
\text { Google My } \\
\text { Maps }\end{array}$ & $\begin{array}{l}\text { PSTs create mobile media } \\
\text { interpretations of everyday } \\
\text { mathematics via Google } \\
\text { My Maps }\end{array}$ & $\begin{array}{l}\text { Mobile phones, mobile } \\
\text { media, computers }\end{array}$ \\
\hline
\end{tabular}

Each MMM iteration began during the fourth class session with PSTs contributing to an online, peer-facilitated discussion about place-based mathematics education (Activity 1). Discussing placebased approaches to school mathematics introduced the mathematics in everyday activity as relevant to classroom teaching and learning. The fifth class session each semester began with PST teams leaving their university classroom and conducting community-based mobile investigations of everyday mathematics phenomena (Activity 2). Categories of mobile investigation were informed by the Common Core Standards for Mathematical Practice (CCSS; National Governors Association, 2010) 
and represented 14 disciplinary concepts and practices: Aesthetics, commerce, conversation, cooperation, development, exclusion and limits, greater and less than, history, inequality, interaction, law, nature, operations and visual. Following mobile investigations of these phenomena across settings, PSTs returned to the classroom with collected media and information (i.e. photographs, video recordings, field notes) and began producing mobile media interpretations (Activity 3). The production of mobile interpretations (Activity 4) occurred for an additional one to two weeks as PSTs authored digital media in Google My Maps to represent how their mobile investigations revealed concepts (like inequality) and practices (such as operations) situated among everyday mathematics in activity.

Because MMM was enacted as part of ongoing design-based research, activity shortcomings motivated iterative refinements to effectively support PSTs in establishing connections among school and everyday mathematics (Author, 2016). Multiple "cycles of invention and revision" (Cobb et al., 2003, p. 10) resulted in modeling mobile investigation and interpretation strategies, training PSTs on effective practices for capturing and collecting evidence of mathematical phenomena, and scaffolding how PSTs prototyped and created their mobile media interpretations. As a complement to the findings of this case, the evolution of MMM across three iterations supported PSTs as they learned to identify and "shape disciplinary relations across community, classroom and online environments" (Author, 2016, p. 79).

\section{Data Collection}

Data for this case were collected from the mobile interpretations PSTs produced during classroom prototyping (Activity 3) and online design (Activity 4). Using media and information collected during community-based mobile investigations, PSTs designed mobile interpretations in Google My Maps as a constructivist meaning-making process (e.g. Taylor \& Hall, 2013). The produced media representing a mobile interpretation was a placemark, or a location-specific digital artifact that included information about a mobile investigation. A placemark could - and often did - 
include descriptive text from field notes, embedded digital media like a photograph or video, and supplemental features like hyperlinks to online mathematics resources (i.e. CCSS).

Figure 1, below, is a representative mobile interpretation placemark from M2 that features a title ("B-cycle biker"), the mobile investigation category "commerce" denoting mathematics in the everyday use of a subscription service, a text description from PSTs' community-based interaction, and a photograph - all of which collectively indicate the specific geographic location where the investigation occurred. In this placemark, PSTs interpreted their investigation of commerce in the context of a bicycle ridesharing service, noting how the disciplinary concepts of rate, cost, and time inform a peer's behavior: “... If you only use the bike for 30 minutes you don't get charged anything additional. So this particular student uses it to get to different classes and places around the city in under 30 minutes. That way he only paid $\$ 20$ for bike use for the year" ( $m 2 . g 2 i 9)$. In total, data collection across iterations comprised 213 mobile interpretation placemarks, including all text, embedded media, and supplementary information. Table 2 presents PSTs' total mobile interpretations by investigation category.

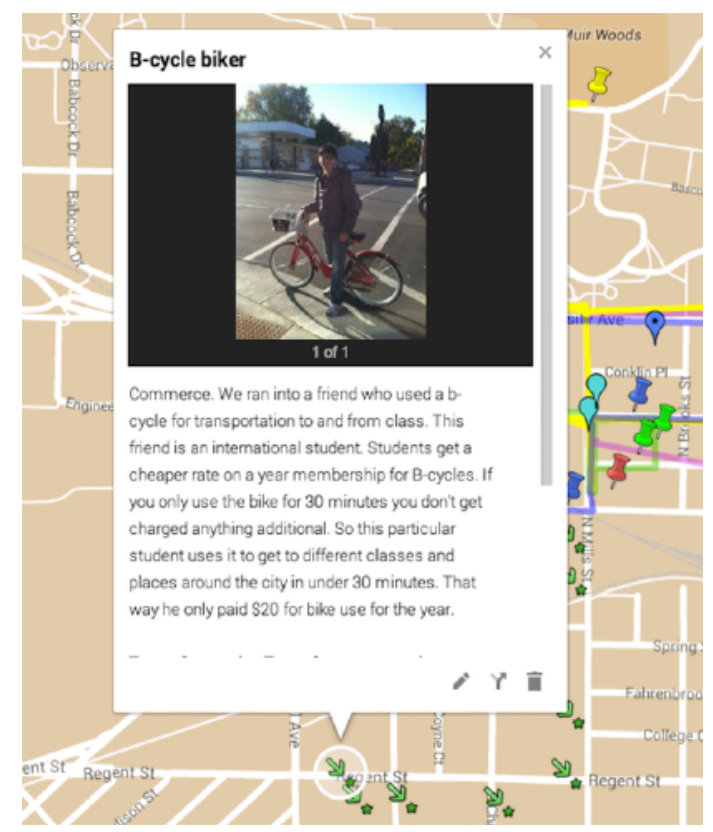

Figure 1. Mobile interpretation placemark of commerce investigation titled "B-cycle biker." 
Table 2: Total mobile interpretation placemarks for each type of mobile investigation

\begin{tabular}{|c|c|c|c|c|}
\hline $\begin{array}{l}\text { Mobile } \\
\text { investigations }\end{array}$ & $\begin{array}{l}\text { M1 mobile } \\
\text { interpretation } \\
\text { placemarks }\end{array}$ & $\begin{array}{l}\text { M2 mobile } \\
\text { interpretation } \\
\text { placemarks }\end{array}$ & $\begin{array}{l}\text { M3 mobile } \\
\text { interpretation } \\
\text { placemarks }\end{array}$ & $\begin{array}{l}\text { Total mobile } \\
\text { interpretation } \\
\text { placemarks }\end{array}$ \\
\hline Aesthetics & 6 & 3 & 7 & 16 \\
\hline Commerce & 6 & 14 & 6 & 26 \\
\hline Conversation & 4 & 0 & 7 & 11 \\
\hline Cooperation & 4 & 1 & 5 & 10 \\
\hline Development & 6 & 9 & 6 & 21 \\
\hline Exclusion and limits & 6 & 1 & 6 & 13 \\
\hline Greater and less than & 7 & 0 & 9 & 16 \\
\hline History & 6 & 2 & 7 & 15 \\
\hline Inequality & 7 & 1 & 4 & 12 \\
\hline Interaction & 4 & 5 & 9 & 18 \\
\hline Law & 6 & 1 & 8 & 15 \\
\hline Nature & 4 & 2 & 7 & 13 \\
\hline Operations & 0 & 4 & 6 & 10 \\
\hline Visual & 6 & 6 & 5 & 17 \\
\hline Total & 72 & 49 & 92 & 213 \\
\hline
\end{tabular}

With PSTs motivated to represent meaningful aspects of their mobile investigations - rather than mandated to produce a specific quantity of placemarks - both the visual style and the total number of mobile interpretations varied among collaboratively authored maps. Figure 2 displays the 49 mobile interpretations PSTs produced and mapped during M2. 


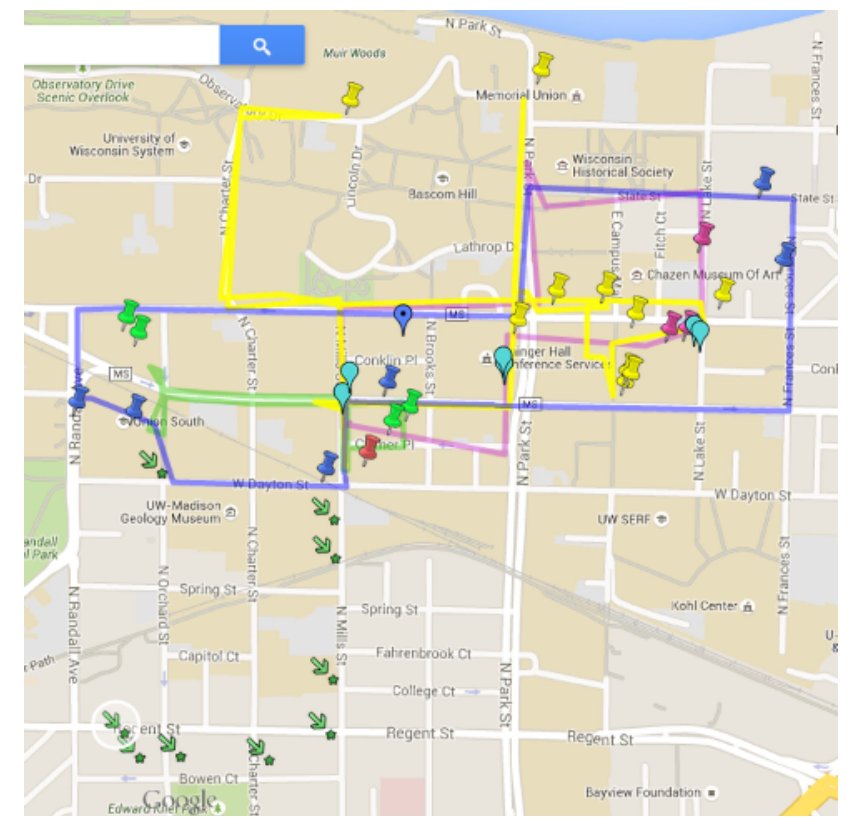

Figure 2. M2 map featuring 49 mobile interpretation placemarks

\section{Data Analysis}

The first phase of data analysis featured inductive coding via the constant comparison method (Patton, 2005). Text from all 213 mobile interpretation placemarks was entered into Dedoose, an online data analysis program. My co-instructor and I independently coded the same 22 randomly selected placemark text samples (10\% of the dataset), and created initial codes and definitions. We then shared and compared codes, and created a revised scheme with uniform definitions. This scheme included 54 codes within six categories. Categories and sample codes included: mathematics concepts (i.e. patterns, rate), settings (i.e. campus, civic), mathematics actions (i.e. exchange, calculation), material objects (i.e. food, signs), sociocultural context (i.e. politics), and time. We then randomly selected another 33 text samples (15\% of the dataset), applied the new scheme, and noted via memoing when multiple codes were associated with the same text. The second coding pass was also used to calculate the percentage of coding agreement; inter-rater reliability was $83 \%$. We applied the final coding scheme to all 213 mobile interpretations. Coding disagreements were noted via audit trail, and resolved or discussed. 
The second phase of analysis identified two types of connections that PSTs produced between school and everyday mathematics as a result of mobile investigation and interpretation. First, a concept-action-object connection (CAOC) was identified when a placemark evidenced the cooccurrence of a mathematics concept, a mathematical action, and a material object. One hundred and two of the 213 mobile interpretations (48\% of the dataset) featured 166 CAOCs. For example, a pricecomparison-food CAOC described how a team of PSTs: “...found the price of a 12-pack of soda and compared it to the price of the same item at Fresh Market" (m1.g3i8).

Second, a school-everyday connection (SEC) was identified when a placemark: a) referenced the CCSS, b) mathematized everyday phenomena as related to a school mathematics practice (i.e. Martin \& Gourley-Delaney, 2014), or c) referred to PST practicum teaching. Ninety-eight of the 213 mobile interpretations (46\% of the dataset) featured SECs. For example, one group's history investigation mathematized a landmark sign: "On the sign next to the Space Communication Antenna, there were a bunch of math facts that could easily be turned into a math problem: Each orbit takes 90 minutes, how long would it take the satellite to orbit 8 times?" (m3.gli13). However, SECs were primarily determined by reference to grade-level standards (Table 3).

Table 3: Quantitative summary of SECs in PST mobile interpretations

\begin{tabular}{lllllll}
\hline Iteration & $\begin{array}{l}\text { SEC via } \\
\text { CCSS }\end{array}$ & $\begin{array}{l}\text { SEC via } \\
\text { Mathematizing }\end{array}$ & $\begin{array}{l}\text { SEC via } \\
\text { Practicum }\end{array}$ & $\begin{array}{l}\text { Total } \\
\text { SECs }\end{array}$ & $\begin{array}{l}\text { Prominent Mobile } \\
\text { Interpretations } \\
\text { (SECs per Interpretation) }\end{array}$ & $\begin{array}{l}\text { Percentage of } \\
\text { Total Mobile } \\
\text { Interpretations }\end{array}$ \\
\hline M1 & 0 & 0 & 1 & 1 & Development (1) & $1 \%$ \\
\hline M2 & 29 & 15 & 1 & 45 & $\begin{array}{l}\text { Commerce (14) } \\
\text { Visual (6) } \\
\text { Development (5) } \\
\text { Interaction (5) }\end{array}$ & $92 \%$ \\
\hline M3 & & & & & & \\
& 47 & 5 & 0 & 52 & $\begin{array}{l}\text { Interaction (6) } \\
\text { Aesthetics (5) } \\
\text { Commerce (5) } \\
\text { Conversation (5) } \\
\text { Greater and less than (5) }\end{array}$ \\
\end{tabular}


Having identified CAOCs and SECs, the third and final analytic phase utilized data visualization techniques inspired by White and colleagues' (2011) Cartesian quadrant depicting divisions between formal and informal learning, and personal and mathematical sense-making. For this case, three connection charts were created to categorize by MMM iteration all PST mobile interpretations into four quadrants. Categorization was based upon two criteria: first, whether or not the given mobile interpretation evidenced PSTs establishing a school-everyday connection (SEC, and delineated by the X-axis); and second, whether or not the given mobile interpretation evidenced a PSTs establishing a concept-action-object connection (CAOC, and delineated by the y-axis). Figure 3 visualizes patterns among the 72 mobile interpretations produced by PSTs during M1, Figure 4 the 49 produced during M2, and Figure 5 the 92 produced during M3.

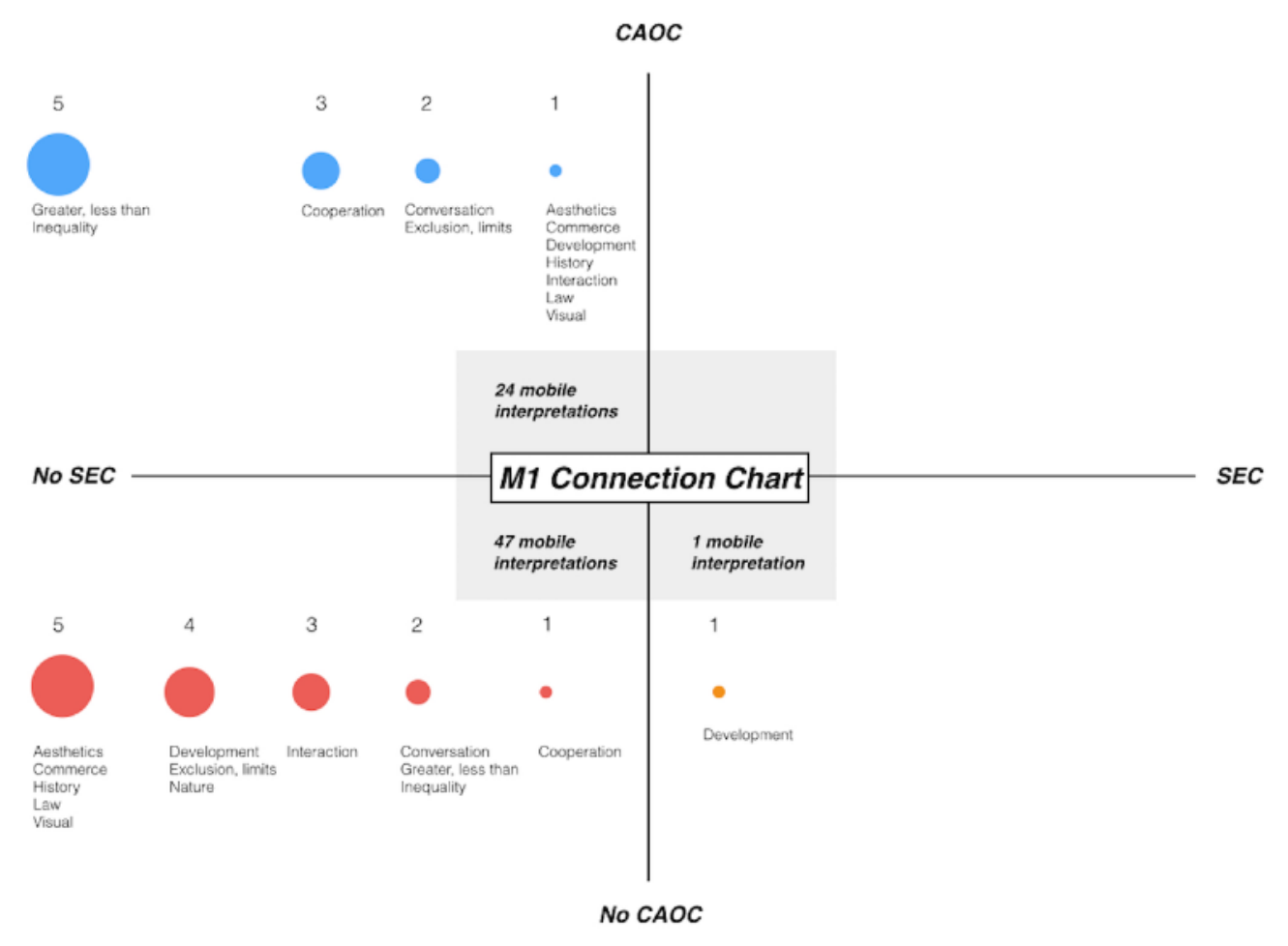

Figure 3. M1 connection chart visualizing disciplinary connections produced by PSTs. 


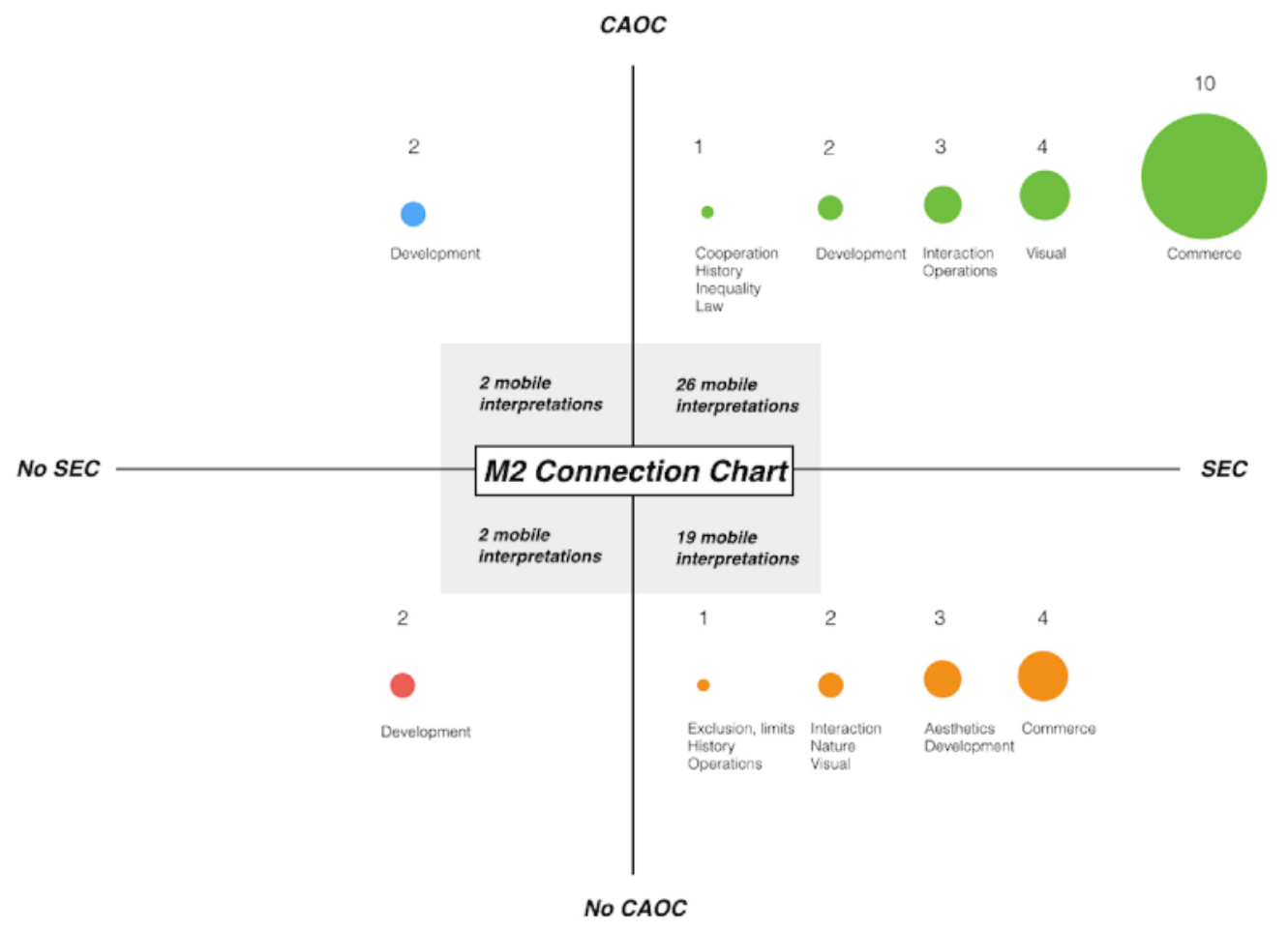

Figure 4. M2 connection chart visualizing disciplinary connections produced by PSTs.

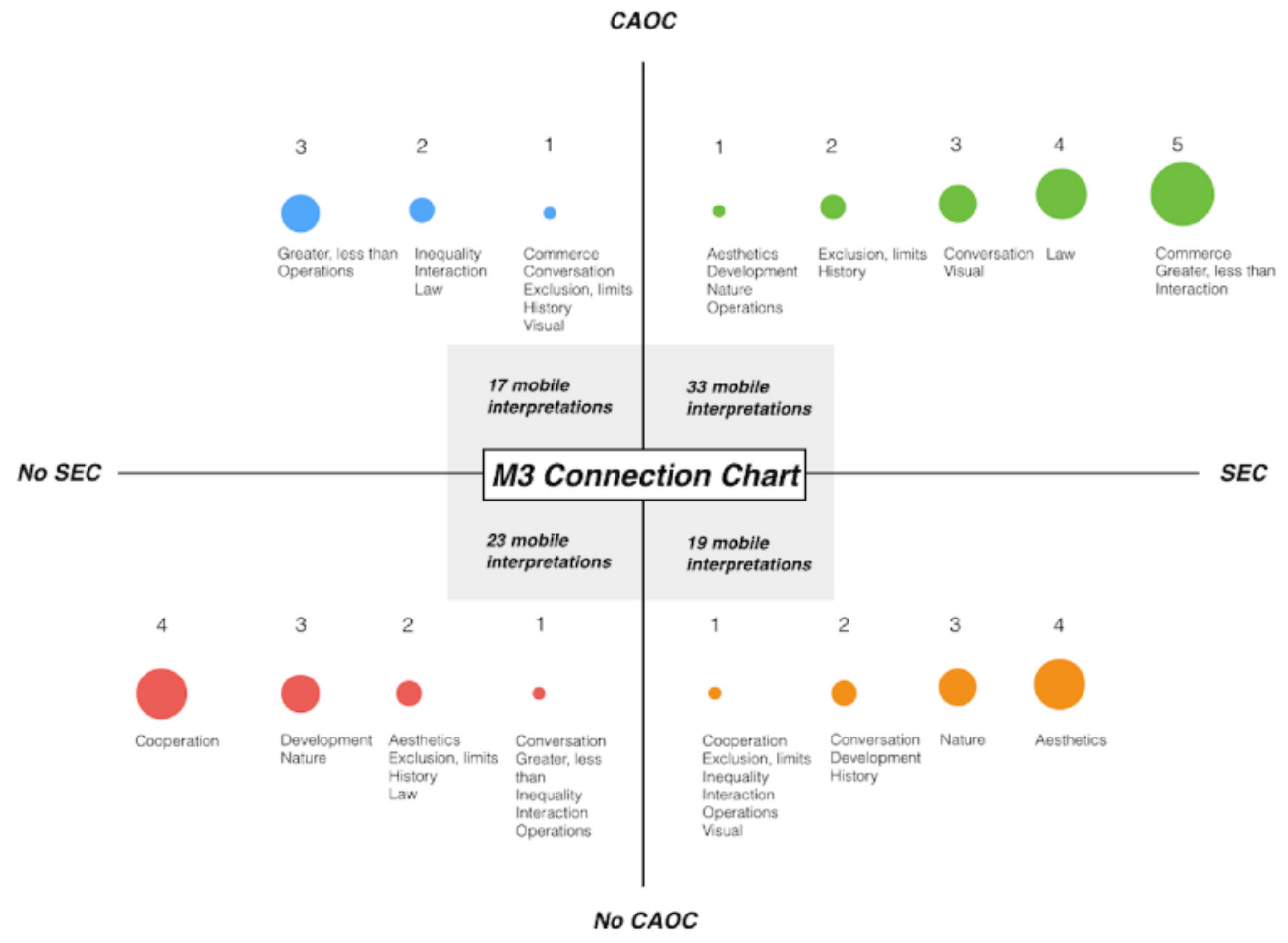

Figure 5. M3 connection chart visualizing disciplinary connections produced by PSTs. 
Within any connection chart quadrant, mobile investigation categories are grouped together, and circles proportionately illustrate - and help to visually compare - the total instances of each category of phenomena. For example, a connection chart's lower left quadrant visualizes mobile interpretations that evidenced neither a CAOC nor a SEC. The M1 connection chart indicates PSTs interpreted five instances each of mathematical aesthetics, commerce, history, law, and visual investigations. When these interpretations were coded, however, the placemark did not evidence either a CAOC or SEC. In contrast, a connection chart's upper right quadrant visualizes mobile interpretations that evidenced both a CAOC and a SEC. The M3 chart indicates PSTs interpreted five instances each of mathematical commerce, greater and less than, and interaction mobile investigations that evidenced both types of connections. Connection charts visualized quantitative and thematic patterns about how PST mobile investigation and interpretation did - and also did not - produce disciplinary connections across settings.

\section{Findings}

Having identified and visualized the CAOCs and SECs evidenced in 213 MMM placemarks, three sets of PST mobile learning outcomes are reported: first, connections PSTs produced among mathematics concepts, mathematical actions, and material objects; second, connections PSTs produced between school mathematics and everyday circumstances; and third, connected disciplinary inquiries, or mobile learning that evidenced interconnected CAOCs and SECs. Collectively, these findings suggest PSTs established disciplinary connections when exploring or participating in commercial and civic activities relevant to their daily lives, such as purchasing food, paying for parking, or participating in commercial transactions. Findings further indicate PST mobile investigation and interpretation excluded particular mathematics concepts and circumstances that were not as immediately familiar to their daily experiences. 


\section{Producing Connections Among Mathematics Concepts, Actions, and Objects}

CAOCs revealed how PSTs connected traditional academic content domains with their observations of out-of-school mathematics practices and objects found in everyday interactions. In M1, one third of all mobile interpretations $(24$ of $72,33 \%)$ featured 33 CAOCs. The most prevalent CAOC was price-comparison-food and appeared in 13 placemarks associated with five different categories of investigation phenomena, including five interpretations of greater and less than, and four instances of everyday inequality. One price-comparison-food connection that described everyday mathematical inequality noted: "Here we had a conversation with the cashier about how much coffee is, compared their price (\$1.85) for a regular coffee to McDonald's (\$1) and Greenbush (\$1.20)" ( $m 1 . g 8 i 8)$. PSTs produced a similar CAOC - price-exchange-food - in six placemarks, all of which represented different investigations of mathematics in activity, specifically commerce, conversation, cooperation, greater and less than, inequality, and interaction. However, two thirds of M1 mobile interpretations did not exhibit CAOCs, including most aesthetics, commerce, development, exclusion and limits, history, interaction, law, and visual investigations. None of PSTs' investigations of nature evidenced a CAOC.

In contrast to M1, slightly over half of the M2 mobile interpretations (28 of 49, 57\%) evidenced a total of 46 CAOCs. The most prevalent CAOC was time-calculation-architecture; PSTs established this connection in six placemarks - among two investigations of commerce and operations in everyday mathematics, as well as in one interaction and one visual investigation. The following description of time-calculation-architecture in an investigation of everyday operations is representative of PSTs interpreting disciplinary concepts and actions as situated outside traditional school settings:

The rates of the State Street Campus Parking Ramp are posted at all of the entrances to the ramp. These rates are written as decimals and apply to the amount of time spent parking in this particular lot. To find the amount of money you owe, you would need to multiply the rate per hour by how many hours you were parked there. Using these rates would give students practice with multiplying decimals with whole numbers and 
decimals with decimals. It would also give them a glimpse as to how much money is actually needed to park in a parking lot. ( $m 2 . g 6 i 5)$

A second trend was ten interpretations of everyday commerce featuring $17 \mathrm{CAOCs}$, including two instances each of time-calculation-architecture, percentage and rate-calculation-architecture, pricecalculation-food, price-exchange-food, and prince-exchange-money. As for mobile investigations not evidencing CAOCs, PSTs did not establish these disciplinary connections in any aesthetics, nature, and exclusion and limits interpretations. Aesthetics and nature are notable omissions, as both phenomena are stereotypically associated with complex mathematics.

Just over half of the M3 mobile interpretations (50 of 92, or 54\%) evidenced a total of 87 CAOCs. Similar to M1, PSTs most frequently described co-occurrences of price-comparison-food; this connection was featured in 18 placemarks, including all eight interpretations of greater and less than phenomena. Price-comparison-food also appeared in four interpretations of mathematics in commerce and other interactions. Perhaps as a result of increased time for M3 media authoring activities, pricecomparison-food descriptions often paired disciplinary connections with nuanced observations of outof-school settings and practices: "We went to Starbucks on the square where Leah" bought the same oz. cup of coffee that Dirk had at Bradbury's. Dirk's cup of coffee was $\$ 1.90$ and Leah’s was $\$ 1.65$. Starbucks could sell cheaper coffee as it is a chain and can subsidize their prices; Bradbury's is a specialty, local cafe where the prices tend to rise" (m3.g4i9). In this CAOC, PST comparison spanned units (i.e. volume, currency), locations (i.e. Starbucks vs. Bradbury's), and business models (i.e. local vs. chain).

While the percentage of M3 investigations featuring CAOCs was almost equivalent to M2 (57\% and 54\%, respectively), the quantity of $\mathrm{M} 3$ instances was more than double M1, and nearly double M2. As an exploratory case, this frequency is not significant in and of itself. However, this difference in descriptive statistics points to notable qualities of PST learning during M3, namely engagement with a

\footnotetext{
${ }^{1}$ All PST names are pseudonyms.
} 
greater range of mathematical concepts (such as cardinality, percentage and rate) and actions (like calculation and representation) in everyday circumstances. Furthermore, M3 CAOCs appeared in nearly every mobile investigation category (all but the five interpretations of mathematical cooperation). Personal familiarity also appears associated with this increased prevalence; interpretations of day-to-day commercial and civic habits (like parking, analyzing sales price, or purchasing a coffee) generally situated PSTs' disciplinary connections among mathematics concepts, mathematical actions, and objects.

\section{Producing Connections among School and Everyday Mathematics}

Only one M1 investigation featured a SEC. This connection occurred during an investigation of mathematical development and concerned construction at a park playground. The PST team's interpretation mathematized this scenario by asking: "How is circumference being used here?" (m1.g8i13). Unlike M1, nearly all M2 investigations (45 of 49, 92\%) featured SECs. This dramatic increase from one MMM iteration to the next likely reflects PST responses to an emphasis on researching and incorporating the CCSS during prototyping (Activity 3) and online design (Activity 4), as reported in Author (2016). Twenty-nine interpretations referenced these formal standards to establish a SEC, as illustrated in the following history investigation:

When walking up to the $13^{\text {th }}$ Floor of the Educational Science Building our group noticed a timeline on the wall that described a Historical Timeline for the School of Education. In $2^{\text {nd }}$ grade students are to learn how to "compare and order whole numbers" and "determine relationships of numbers 11000." Using a number line, students will be able to look at relationships to events that have happened in history, and compare their relationships based on the size of the year. $(m 2 . g 7 i 1)$

M2 SECs were less frequently produced by PSTs mathematizing everyday phenomena. These SECs occurred in one third of interpretations (15 of 45,33\%) as PSTs mathematized everyday scenarios or objects, often by creating school mathematics problems: "You can work with bus stops to create problems about time addition and subtraction, geometric shapes and the path a bus might travel, and the 
distance a bus might travel versus the distance of you walking" (m2.g4i3). In only one placemark did PSTs produce a SEC by referencing their own practicum teaching: "From the 10th floor of Lakeview Mall Tower, we got a great view of campus from above. We started talking about all the different projects that could be done with planning a city and landscaping. Melissa and Kari are currently teaching a unit on beginning geometry in their practicum site, and are planning to have students design their own cities" (m2.g8i7).

The trend observed in M2 - that PSTs regularly referenced CCSS to establish SECs - persisted during M3. While fewer overall placemarks exhibited SECs (52 of 92, 57\%), a higher percentage of these interpretations were affiliated with the CCSS (47 of 52, 90\%). When PSTs produced SECs in M3, they very likely did so by referring to a formal standard. PSTs mathematized everyday phenomena in only five M3 interpretations. For example, when PSTs produced a placemark about a nature investigation they noted: "Also *fun fact* the slope of trees changes when planted on a hill" $(m 3 . g 7 i 6)$; in this instance, the topography of a hillside is expressly connected to the more formal concept of slope. Like M1, PSTs never referenced practicum teaching experiences to establish a SEC. A final trend in M3 SECs was the inclusion of text hyperlinked to online resources. Nearly all SECs that referred to CCSS (35 of 47, 92\%) were linked to online mathematics resources, such as standards documents or sample lessons.

\section{Producing Connected Disciplinary Inquiries}

The upper right quadrant of MMM connection charts visualizes mobile interpretations that evidenced both CAOCs and also SECs. These instances, termed connected disciplinary inquiries, are distinguished by the convergence of both connection types; concept-action-object and school-everyday mathematics connections are interconnected. Three qualities of connected disciplinary inquiries suggest PST were engaged in more robust mobile and mathematics learning. First, and like CAOCs, connected disciplinary inquiries evidenced linkages among more formal content domains and 
mathematics found in less formal and out-of-school activity. Second, and like SECs, connected disciplinary inquiries evidence mathematical relations crossing multiple settings, including schoolbased, out-of-school, and online contexts. Finally, connected disciplinary inquiries suggest that when PSTs' mobile learning attended to relations among multiple sources of mathematical sense-making, the outcomes of their investigations and interpretations transcended (what are often perceived as) the rigid boundaries separating school from community, discrete disciplinary concepts from fluid everyday activity, and interest-driven from academically-oriented learning (i.e. Gutiérrez, 2012). The characteristics of connected disciplinary inquiries are important to detail so as to better understand and, ideally, create the conditions for - more nuanced cross-setting mobile learning in mathematics teacher education.

PSTs did not generate any connected disciplinary inquiries during M1. Across all MMM iterations, however, slightly more than one quarter of PSTs' mobile interpretations (59 of 213, 28\%) evidenced this co-occurrence of connection types. In M2, slightly more than half of PSTs' M2 placemarks (26 of 49,53\%) evidenced connected disciplinary inquiries. Among this subset, the most prominent category of mobile investigation was commerce, followed by investigations of everyday visual, interaction, and operations phenomena. All six occurrences of the time-calculation-architecture CAOC were featured in this M2 subset, and in five of these instances the interconnected SEC was established through mathematizing an everyday circumstance. Regarding the SECs of this M2 subset, half (13) were established via references to CCSS and half evidenced mathematized everyday phenomena. Notably, ten connected disciplinary inquiries were generated by PSTs investigating and interpreting various commercial activities.

During M2, PST learning featured questioning and problem-posing practices in order to generate many of their connected disciplinary inquiries. For example, a interaction investigation exhibiting time-calculation-architecture mathematized PSTs' community-based conversation by 
suggesting specific school mathematics opportunities: “At this bus stop we looked at and talked about how this could be used to teach students about time. The students would have to be able to read the different times and could determine how much time until the next bus comes or by how much time they missed the bus" (m2.g6i4). Similarly, an interpretation of law in everyday mathematics - and which evidenced both price-comparison-food and price-exchange-food CAOCs - contained questions of social, geographic, and economic import that further mathematized the everyday activity of purchasing groceries:

This man is purchasing groceries and paying a designated amount per item. Sometimes these designated prices can be negotiated (due to sales and expiration dates). Prices for items are generally easy to locate on nearby signs. The total of prices is displayed on a monitor before the customer pays for his groceries. Questions: Is what people buy related to salary/income? What demographic of people shop at Fresh? How do the prices at Fresh compare to other grocery stores in other parts of City?" (m2.g3i8).

Slightly more than one third of PSTs' M3 mobile interpretations (33 of 92, 36\%) were also connected disciplinary inquiries. This subset prominently featured PST investigations of commerce, greater and less than, interaction, and law in everyday mathematics. The CAOCs within this subset mirrored general M3 trends; 12 of the 18 price-comparison-food and four of the eight height and weight-comparison-food connections appeared in connected disciplinary inquiries. Unlike M2, a majority of M3 SECs in this subset were established by PSTs referring to the Common Core (30 of 33, 91\%). Perhaps because of these prominent CCSS references, in only two instances did PSTs ask questions or pose problems, a notable difference from PST learning practices during M2. Another M3 trend among connected disciplinary inquiries was a focus upon PSTs' everyday commercial rituals, particularly those that involved food. Specifically, PST learning drew upon disciplinary concepts such as price, height and weight, and cardinality, as well as mathematics actions like comparison, calculation, and exchange, to describe their habits associated with morning coffee, groceries, or other beverage-related pursuits (19 of 33, or 58\%, of M3 connected disciplinary inquiries). In summary, with 
M1 absent any connected disciplinary inquiries, it appears that the 59 of 141 M2 and M3 mobile interpretations $(42 \%)$ that did evidence interconnected CAOCs and SECs were often produced through PST participation in familiar commercial and civic rituals linked with reference to formal mathematics standards.

\section{Discussion}

This case study of PST learning reveals how the curriculum module MMM guided mobile investigations and interpretations of mathematics concepts situated among everyday activities and settings, and supported PSTs as they practiced connecting school-based with so-called real world mathematics. While MMM enabled PST to make such connections through investigation and interpretation of mathematics across multiple settings, a more complex - and critical - reading of this study's findings reveals outstanding opportunities that can inform subsequent mobile learning design and enactment. Given the importance of articulating design principles to guide equitable participation in science and mathematics education across settings (Penuel, Lee, \& Bevan, 2014), this discussion considers first study limitations and then design recommendations for further cross-setting mobile learning in mathematics teacher education.

\section{Limitations}

There are several limitations to this study that should prompt others to iterate upon this initial design-based research. First, this study was conducted within a single mathematics methods course, a limitation of scale and perspective not atypical of practitioner-oriented teacher education inquiry. Differences in institution type, geography, and program context would invariably alter implementation and PST learning outcomes. Data collection was also limited to PSTs' interest-driven and peersupported media production, whereas other mobile learning studies have equipped participants with, for instance, GPS devices (Taylor \& Hall, 2013) to gain interdependent perspectives on the ways in which learners negotiate information and social interaction across multiple activity-rich settings. A similar 
approach to documentation could have generated a more diverse corpus of data for the purposes of analyzing PST learning.

A second limitation concerns how curriculum modules like MMM might support PSTs' development of pedagogical knowledge and practice. From an instructional perspective, it is important that PSTs learn to connect children's mathematical thinking with community-based funds of knowledge outside the classroom (Aguirre et al., 2013). Furthermore, developing technological pedagogical content knowledge is a necessary disposition for PSTs, with many often struggling to cultivate pedagogies that effectively leverage learning technologies (e.g. Martinovic \& Zhang, 2012). Together, these aims can be mutually supportive of a mobile learning research agenda in mathematics teacher education that is rooted in K-12 students' disciplinary sense-making and cultural communities, while simultaneously directed at PSTs' practice-focused development of specialized technological pedagogical knowledge.

\section{Design Recommendations for PST Mobile Learning}

The convergence of mobile learning and mathematics teacher education should be designed, first and foremost, according to connected learning principles (Ito et al., 2013). As a contemporary synthesis of learning and design principles rooted in sociocultural theory, connected learning suggests that when (K-12) student participation is openly networked around a shared purpose, is peer-supported and production-centered, and is driven by interest, the possibility for more equitable academic, economic, and civic engagement arises across multiple settings (Garcia, 2014). This study of PST mobile investigation and interpretation adapted connected learning design principles and learning practices within a teacher education context.

Connected disciplinary inquiries, for instance, indicate mobile repertoires can situate PSTs' mathematics education across settings to advance their academic, interest-driven, and professionally relevant learning. Yet only one in four placemarks produced by PSTs indicated such interconnection 
among CAOCs and SECs. Supporting PSTs' connected disciplinary inquiry was not an a priori objective; only because of affinity with general MMM goals did attention to these more robust and varied disciplinary connections emerge through iterative redesign efforts (Author, 2016). Furthermore, and as noted, PST media production evidenced mixed outcomes; no connected disciplinary inquiries were produced by PSTs in M1, then slightly more than half of the mobile interpretations in M2, and finally slightly more than a third in M3. Given concern for connecting mathematics learning in out-ofschool and cultural settings with formal school-based teaching (Civil, 2014; Martin \& GourleyDelaney, 2014), the design principles articulated by connected learning may usefully guide the integration of mobile learning practices within teacher education programs, thereby creating the conditions for more nuanced cross-setting inquiry that connects academic with everyday mathematics.

Mobile mathematics learning - like other community-oriented efforts in mathematics teacher education (e.g. Aguirre et al., 2013) - should also carefully manage how PSTs are encouraged to connect mathematics as activity with mathematics in activity. That more than three fourths ( 76 of 98 , 78\%) of all SECs across MMM iterations were established via reference to CCSS may be interpreted as both a cause for celebration and also as a shortcoming. On the one hand, PSTs routinely connected their investigations of everyday, or so-called informal, phenomena to a leading formal school mathematics resource, demonstrating an approach that provisionally bridged persistent disciplinary rifts between community and curriculum (Gutiérrez, 2012). It is necessary that PSTs familiarize themselves with standards-based frameworks through meaning-making experiences during their teacher preparation. Alternatively, by primarily anchoring interpretations of everyday mathematics to the Common Core, PSTs may have also obscured - or worse, ignored - potential linkages with a wider variety of academic mathematics, such as the use of real world data, or their practicum teaching experiences. 
Trends in PST SEC production need to also be considered within the context of MMM enactment. At the time of their participation, PSTs had limited experience in schools teaching mathematics; practicum field placements had begun only one week prior to MMM. As such, it is unsurprising that PSTs had difficulty drawing upon their own instructional experiences to establish SECs. As for mathematizing everyday phenomena, when they did so PSTs often accessed isolated factual knowledge (i.e. "Also *fun fact* the slope of trees changes when planted on a hill"), or asked generic questions (i.e. "How is circumference being used here?"). These findings suggest it is important to question, and manage, when mobile learning may most usefully complement PSTs' mathematics teacher education. Within a given semester or teacher education program, curricular integration should align more closely with PSTs' ongoing instructional experiences in practicum classrooms, especially if diverse connections between school and everyday mathematics are an intended outcome of cross-setting mobile learning.

Another design recommendation concerns qualifying whose everyday mathematics are investigated and interpreted during mobile learning. Findings from this study further demonstrate it is important to consider for whom activities are designed when mathematics (teacher) education leaves the classroom and engages in inquiry across everyday and cultural settings (Civil, 2014; White \& Martin, 2014). PSTs primarily investigated and interpreted their everyday mathematics experiences, often in relation to the people, places, and circumstances of personal familiarity. Prominent CAOCs, like price-comparison-food, reflected the curiosities of undergraduate students attending a state's flagship research university and living in a "college town" overpopulated by cafés and convenience stories. Familiar campus locations became pedagogical for these PSTs, with their everyday street corners and shops renegotiated as complementary to both classroom learning and mathematics content domains. 
That PSTs primarily investigated and interpreted the everyday mathematics of their daily financial, interpersonal, and civic relations is not a limitation per se. Rather, this confirms a leading insight from mobile learning research: "Mobile media personalize learning experiences, so that students pursue learning trajectories driven by interest" (original emphasis; Squire, 2013, p. 187). Yet in one reflection following M2, a PST wanted to learn about "how to focus on my students' interests in the world around them rather than my own. I can see how there could be some issues there, because my interests may not be the same as those of my students" ( $m 2 . e s 20)$. Improving designs for mobile learning initiatives in mathematics teacher education should expressly concern how and for whom learning is personalized, ideally shifting attention away from PST interests and to those of their current and future K-12 students. Such approaches would complement efforts whereby PSTs have investigated their students' cultural and community-based funds of knowledge, and then leveraged these connections to inform culturally relevant mathematics instruction (Aguirre et al., 2013; Gutiérrez, 2012). The lens of PST mobile investigation and interpretation should focus upon clarifying connections among school-based mathematics and K-12 students' out-of-school interests, cultures, and communities.

Finally, mobile learning research in mathematics teacher education should attend to the dynamics of teacher educator facilitation. Among the dilemmas of design-based research is concern for the extent to which a designed innovation evolves over time, and how participants' emergent learning outcomes are valued, managed, and referenced in subsequent redesign and enactment efforts (Cobb et al., 2003). In this study it is reasonable to conjecture that PSTs would have approached mobile investigation differently if, prior to leaving the classroom, they reviewed a rubric that introduced CAOCs and explained why these types of connections were an important aspect of connected disciplinary inquiry. Similarly, had PSTs known that their placemark interpretations were to be evaluated based upon different types of SECs, they may have referenced CCSS less frequently. Cross- 
setting inquiry in K-12 social studies and science education has required explicit scaffolds for middle grades and high school students (e.g. Squire, 2010; van't Hooft, 2013); future research might consider providing supplemental scaffolds in advance of mobile learning to enhance PSTs' "cognizance of how their own experience as students provides a blueprint for the learning environments they may need to generate in their future classroom" (Carmona et al., 2011, p. 366). Advancing mobile learning in mathematics teacher education will likely require more explicit scaffolds so that repertoires of practice - like mobile investigation and interpretation - more meaningfully establish disciplinary connections across the boundaries of school and everyday learning (Author, 2016).

\section{Conclusion}

There is growing concern that (preservice) teachers develop novel skills, creative dispositions, and the ability to facilitate more culturally relevant and equitable mathematics education (Civil, 2014; Gutiérrez, 2012). Advances in mobile learning theory and practice further challenge (teacher) educators to examine how it is not only possible, but perhaps also beneficial, to connect mathematics education within school settings to learners' everyday, community-based, and cultural forms of knowledge and practice (e.g. Martin \& Gourley-Delaney, 2014; Wijers et al., 2010). In this respect, mobile learning curriculum modules like MMM appear a promising means of addressing long-standing fissures in mathematics education: "Most constructivists agree that experiences with concepts and relations in school mathematics are typically different from experiences with those concepts in the real world. If the learners in school are to make sense of the worlds around them, then the school-world and the real-world need to intersect" (Kim \& Sharp, 2000, p. 319; see also Aguirre et al., 2013; White \& Martin, 2014). MMM supported PSTs as their interest-driven and peer-supported investigations identified specific content domains as rich sources of mathematics in everyday activities. However, other mathematics concepts and practices were either seldom investigated, only vaguely described, or not representative of K-12 students' interests and cultures. This case study of PST learning in MMM 
offers a design template that may be useful for subsequent attempts at situating mathematics teacher education outside the classroom and across multiple settings through mobile learning.

\section{References}

Aguirre, J. M., Turner, E. E., Bartell, T. G., Kalinec-Craig, C., Foote, M. Q., Roth McDuffie, A., \& Drake, C. (2013). Making connections in practice: How prospective elementary teachers connect to children's mathematical thinking and community funds of knowledge in mathematics instruction. Journal of Teacher Education, 64(2), 178-192.

Author. (2016). Blinded for review.

Banks, J.A., Au, K.A., Ball, A.F., Bell, P., Gordon, E., Gutierrez, K.D., Brice Heath, S., Lee, C.D., Lee, Y., Mahiri, J., Suad Nasir, N., Valdes, G., \& Zhou, M. (2007). Learning in and out of school in diverse environments: Life-long, Life-wide, and Life-deep. LIFE Center: University of Washington, Stanford University, SRI International.

Brown, J. S., Collins, A., \& Duguid, P. (1989). Situated cognition and the culture of learning.

Educational Researcher, 18(1), 32-42.

Bull, G., Thompson, A., Searson, M., Garofalo, J., Park, J., Young, C., \& Lee, J. (2008). Connecting informal and formal learning experiences in the age of participatory media. Contemporary Issues in Technology and Teacher Education, 8(2), 100-107.

Carmona, G., Domínguez, A., Krause, G., \& Durán, P. (2011). Emergent public spaces: Generative activities on function interpolation. Contemporary Issues in Technology and Teacher Education, 11(4), 362-381.

Civil, M. (2014). STEM learning research through a funds of knowledge lens. Cultural Studies of Science Education, 1-19.

Cobb, P., Confrey, J., diSessa, A., Lehrer, R., \& Schauble, L. (2003). Design experiments in educational research. Educational Researcher, 32(1), 9-13.

Dewey, J. (1897/1959). My pedagogic creed. In J. Dewey (Ed.), Dewey on education (pp. 19-32). New York, NY: Teachers College Press.

Ferry, B. (2009). Using mobile phones to enhance teacher learning in environmental education. In: J. Herrington, A. Herrington, J. Mantei, I. Olney, \& B. Ferry (Eds.), New technologies, new pedagogies: Mobile learning in higher education (pp. 45-55). Wollongong, AU: University of Wollongong.

Fosnot, C. T. (2013). Constructivism: Theory, perspectives, and practice. New York, NY: Teachers College Press. 
Garcia, A. (Ed.). (2014). Teaching in the connected learning classroom. Irvine, CA: Digital Media and Learning Research Hub.

Gutiérrez, R. (2012). Embracing Nepantla: Rethinking "Knowledge” and its Use in Mathematics Teaching. REDIMAT - Journal of Research in Mathematics Education, 1(1), 29-56.

Ito, M., Gutiérrez, K., Livingstone, S., Penuel, B., Rhodes, J., Salen, K. et al. (2013). Connected learning: An agenda for research and design. Digital Media and Learning Research Hub.

Kim, M. K., \& Sharp, J. (2000). Investigating and measuring preservice elementary mathematics teachers' decision about lesson planning after experiencing technologically-enhanced methods instruction. Journal of Computers in Mathematics and Science Teaching, 19(4), 317-338.

Lave, J. \& Wenger, E. (1991). Situated Learning: Legitimate Peripheral Participation. Cambridge, UK: Cambridge University Press.

Martin, L., \& Gourley-Delaney, P. (2014). Students' images of mathematics. Instructional Science, 42(4), 595-614.

Martinovic, D., \& Zhang, Z. (2012). Situating ICT in the teacher education program: Overcoming challenges, fulfilling expectations. Teaching and Teacher Education, 28(3), 461-469.

National Governors Association Center for Best Practices. (2010). Common Core State Standards for Mathematics. Washington, DC: National Governors Association Center for Best Practices and the Council of Chief State School Officers.

Patton, M. Q. (2005). Qualitative research. Hoboken, NJ: John Wiley \& Sons, Ltd.

Penuel, W. R. (2014). Studying science and engineering learning in practice. Cultural Studies of Science Education, 1-16.

Penuel, W. R., Lee, T., \& Bevan, B. (2014). Designing and building infrastructures to support equitable STEM learning across settings. Cambridge, MA: Research and Practice Collaboratory.

Sharples, M., Taylor, J., \& Vavoula, G. (2007). A theory of learning for the mobile age.

In Medienbildung in neuen Kulturräumen (pp. 87-99). VS Verlag für Sozialwissenschaften.

Squire, K. (2009). Mobile media learning: Multiplicities of place. On the Horizon, 17(1), 70-80.

Squire, K. (2010). From information to experience: Place-based augmented reality games as a model for learning in a globally networked society. Teachers College Record, 112(10), 2565-2602.

Squire, K. (2013). Mobile media learning: Ubiquitous computing environments for the mobile generation. In C. Mouza \& N. Lavigne (Eds.), Emerging technologies for the classroom: A learning sciences perspective (pp. 187-204). New York, NY: Springer. 
Stevens, R. (2013). What counts too much and too little as math. In B. Bevan, P. Bell, R. Stevens, \& A. Razfar (Eds.), LOST opportunities: Learning in out-of-school time (pp. 65-83). New York, NY:

Springer.

Taylor, K. H., \& Hall, R. (2013). Counter-mapping the neighborhood on bicycles: Mobilizing youth to reimagine the city. Technology, Knowledge and Learning, 18(1-2), 65-93.

van't Hooft, M. (2013). The potential of mobile technologies to connect teaching and learning inside and outside of the classroom. In C. Mouza \& N. Lavigne (Eds.), Emerging technologies for the classroom: A learning sciences perspective (pp. 175-186). New York, NY: Springer.

White, T., Booker, A., Ching, C. C., \& Martin, L. (2011). Integrating digital and mathematical practices across contexts: A manifesto for mobile learning. International Journal of Learning, 3(3), 7-13.

White, T., \& Martin, L. (2014). Mathematics and mobile learning. TechTrends, 58(1), 64-70.

Wijers, M., Jonker, V., \& Drijvers, P. (2010). MobileMath: exploring mathematics outside the classroom. ZDM, 42(7), 789-799.

Yackel, E., \& Cobb, P. (1996). Sociomathematical norms, argumentation, and autonomy in mathematics. Journal for Research in Mathematics Education, 27, 458-477. 